through the row of perforations at $F$, into the next shelf, and so on until it escapes at $\mathrm{M}$. The size of the holes at the alternate ends of the shelves is such, that no three of them will admit sufficient air for a single respiration; therefore the air passes through all and over the whole of the superficies charged with ether.

The following are some notes of cases in which ether was administered.

CASE I.- (In this and the four following cases ether was given on a towel.)-A man with a sinus in the region of the hip was brought under the influence of the ether in eight minutes. There was no struggling nor lividity. He was under its influence altogether a quarter of an hour, during which time he took six ounces. He was very sick directly after the operation, and continued so for a short time, but passed a good night and felt quite himself the following morning.

CASE II.-A little girl aged II, with a sinus over the lower jaw, was brought under the influence of ether in six minutes. There was no struggling nor sickness. She took about three ounces.

CASE III. - A woman aged 30, with cancer of the breast, was brought under the influence of ether in a little over four minutes. There was no struggling. The operation lasted twenty minutes, during which time she took six ounces. She was not sick till the following morning, then twice.

CASE IV.-A woman aged I9, with sinuses around the ankle-joint, was brought under its influenee in three minutes. The operation lasted three minutes more, and she took three ounces. There was no struggling nor sickness.

CASE V. - A man aged 40 was brought into the theatre for extirpa. tion of the eyeball. He struggled a good deal, but was brought under the influence of ether in four minutes. The operation lasted four minutes more, during which time he took five ounces. He was very sick.

CASE vi.-(In this and the following cases the inhaler above described was used.) -A child, with abscess of the thigh and supposed necrosis, required three minutes to be brought under the influence of ether, and was kept under for eight minutes longer. She took three ounces; but the mouth-piece was too large for the face, so that a good deal of ether was wasted. She had no sickness.

CASE VII. - A man was operated on for necrosis of the tibia. $\mathrm{He}$ had been a soldier, and drank rather freely. He was brought under the influence of ether in five minutes, after a good deal of struggling. He was kept in a state of anæsthesia for six minutes, and took during that time about three ounces. His pulse, during the administration, went up to 140 , and once he became rather livid. He had no sickness.

CASE VIII was one of recurrent cancer in the breast and axilla of a medical man. He had been operated upon twice before, each time having had chloroform, which nearly proved fatal the last time. $\mathrm{He}$ went off very quietly, without any struggling, and was under the influence of ether in four minutes. The operation lasted thirty-five minutes, during which time he took three and a half ounces. He was slightly sick on the return of consciousness.

CASE IX.-A man with necrosis of the elbow-joint was brought under the influence of ether in four minutes. The operation lasted twenty minutes, during which time he took about three ounces. The pulse, before inhalation, was 96 ; during it, I14; after it, 104. There was no lividity nor rigidity; but he was sick before he recovered consciousness.

CASE X.-A man with necrosed bone in the stump of the thigh was brought under the influence of ether in four minutes. Before he was quite unconscious there was great rigidity, and twice he became very livid. The operation lasted eighteen minutes, and he took about three ounces. He was very sick. His pulse before, during, and after the operation was $\mathbf{I} 42$. He was a very nervous subject.

CASE XI. - A lady on whom iridectomy was performed for glaucoma was brought under the influence of the ether in three minutes. There was neither rigidity, lividity, nor sickness. She took about an ounce for double iridectomy.

CASE XII was one of a man with a large tumour in the axilla. His pulse before operation was 96 . He was brought under the influence of ether in five minutes. The operation lasted thirty minutes, the ether being kept up nearly all the time. Towards the end of the operation his pulse became very weak-almost imperceptible-but he soon rallied after an enema of brandy. He had no sickness.

The sickness after ether occurs just about as often as after chloroform, and it is more violent while it lasts, but it does not continue nearly so long. In some cases with ether there is a marked increase in the flow of saliva, but not in all. Cases IX and $x$ had had chloroform in previous operations, and both preferred it to ether. They said that chloroform was less suffocating, and more pleasant to breathe. The pupil under ether is generally dilated. Having given chloroform for more than two years without a fatal case, I think it rather too soon to give an opinion of the superiority of ether.

In Case I, ether was administered a second time by means of the inhaler, with greater comfort than by the towel. The patient was sick immediately afterwards, but this did not continue.

\section{DEATH FROM CHLOROFORM.}

By CHRISTOPHER S. JEAFFRESON, EsQ.,

Surgeon to the Newcastle Eye Infirmary ; to the Children's Hospital ; and Assistant-Surgeon to the General Infirmary.

I HAVE read with great interest the highly practical and interesting remarks of Dr. Jones upon the administration of chloroform; and although I fully concur with him that the dangerous symptoms produced by anæsthetics, especially chloroform, may come on suddenly or gradually, I cannot admit that therefore the deaths from these agents should be classified as avoidable and unavoidable. I say this, because I firmly believe that, in many of the cases where the most sudden and death-like symptoms are instantaneously developed, actual death is avoidable, and may still be averted, provided no time is lost in (at that time) the useless pantomimics of dashing water upon the face, applying ammonia to the nostrils, and various other efforts which are usually resorted to. In these cases, the tongue having been drawn forward, immediate recourse should be had to artificial respiration, and, in spite of all appearances of death, this should be continued for at least three quarters of an hour.

During a large hospital practice, I have administered and assisted in the administration of chloroform several thousands of times; and happy am I to say that I have never witnessed a death, although on two occasions, if I had listened to the advice of bystanders, I fear I should have done so. In each of these cases, the heart's action failed suddenly, and respiration became imperceptible. The bystanders supposed the patient dead, as did I also myself ; nevertheless, in one case, after thirty minutes, in the second case, after twenty minutes, of artificial respiration persistently and energetically carried on, symptoms of animation returned, and the patients perfectly recovered. I think many cases are lost in the two or three minutes' delay which generally elapses between the appearance of the dangerous symptoms and the adoption of artificial respiration, a complete stasis occurring in the pulmonary circulation, which cannot afterwards be overcome; and $\mathbf{I}$ would direct the attention of the profession to this point.

\section{ETHER AS AN AN ESTHETIC. \\ By HENRY GREENIWAY, Eso., Plymouth.}

A FEw years since, owing to the numerous accidents in the administration of chloroform, a compound of ether, chloroform, and rectified spirit, was brought before the notice of the profession (by whom I now forget) as a safe and reliable anæsthetic. Although apparently safe, its action, when I employed it, was slow, and at times imperfect. It shortly afterwards occurred to me that the ether would be of greater value if administered separately for producing the first stage of anæsthesia, the anæesthesia being then completed with chloroform. In the few cases where $I$ adopted this plan, and then only because $I$ thought, from the aspect of the patient, the administration of chloroform simply would prove unsafe, the results were satisfactory. By following this precaution in every case requiring an anæsthetic, and by interposing with ether (as practised by Dr. Jones of St. George's Hospital) whenever chloroform is seriously affecting the respiration or pulse, I believe we may still regard the agent, so long relied on by Sir James Simpson, as a "good servant", and one possessing advantages over ether simply. That chloroform, even thus employed, or any other anæsthetic, may never or very seldom prove a "bad master", it must be properly administered, and we must be able to say, with some degree of certainty, what cases are unsuitable for its administration. To this end I think the attention of investigators should be chiefly directed.

\section{ACUTE INVERSION OF THE UTERUS.}

By Thomas Joyce, M.D., Rolvenden.

M. B., aged 27, a slim, delicate looking woman, was in labour with her third child. In each previous labour flooding to a dangerous extent had occurred. The present labour progressed naturally but slowly, and a dose of ergot was given. After the birth, I requested the nurse in attendance to tie the cord and remove the child whilst I devoted my 
attention exclusively to the womb and endeavoured to prevent another flooding. I accordingly kept up firm pressure on the abdomen with my left hand ; and, the parietes being very thin, I was enabled to grasp the womb, which contracted fairly. After waiting a few minutes, I requested the nurse to put the cord gently on the stretch, whilst I ran my right hand up it and removed the placenta, still keeping the left hand on the abdomen. The placenta was a very large one, and during its extraction I was conscious that a considerable amount of suction power was exerted by it in its descent, the edges being closely applied to the vaginal walls. Immediately after its extraction I missed the womb from the abdomen, and hæmorrhage commenced. Believing it due to relaxation of the womb, I employed the usual means-i.e, cold, pressure, etc.; but, as it continued, and the woman was rapidly blanching, I prepared to inject some solution of perchloride of iron. On passing my left hand into the vagina to remove the clots and guide the injecting tube, I came on a firm round tumour, filling the vagina and almost presenting at the vulva. This proved to be the uterus completely inverted. It was grasped by the fingers of the right hand and steadily pressed upwards, when it quickly resumed its proper position, the tips of the fingers being drawn into the cervix during the last stage of the process. The hrmorrhage ceased at once. A pad and binder were adjusted, and a dose of ergot and opium given. Convalescence progressed naturally.

In this case I have no doubt the inversion was produced by the suction power exerted by the placenta in its descent, aided by manipulation of the fundus through the attenuated abdominal walls.$$
\text { REPORTS }
$$$$
\text { or }
$$ \\ MEDICAL AND SURGICAL PRACTICE IN THE HOSPITALS OF GREAT BRITAIN.}

\section{ST. BARTHOLOMEW'S HOSPITAL.}

Operations, Saturday, November zOTH, 1872.

Lithotomy in a Boy.-Mr. Callender extracted a large calculus from the bladder of a boy about i2 years of age, whose health seemed to be very indifferent. His legs were much bent from rickets, and the pubic arch was very small. The stone was about an inch and a half long, three-quarters of an inch wide, and flattened very like an ordinary pebble. There was considerable difficulty in bringing the stone through the wound in consequence of the smallness of the ischio-rectal fossa, otherwise the operation had nothing peculiar.

Cancer of the Breast. - Mr. Callender also removed the greater portion of the right breast of a woman, the cancer beginning to degenerate actively. It involved the subcutaneous areolar tissue over the gland, and the skin was adherent to it, though not also involved. The glands in the axilla were quite free also from any trace of the disease, and the patient has every chance of a good recovery.

\section{GUY'S HOSPITAL.}

Operations, Tuesday, December 4Th, 1872.

Exostoscs into Orbit and from Frontal Sinus. - The patient, a young man aged 24, an ostler, first observed some slight protrusion of the right eyeball five years ago, and the protrusion had increased slowly, but surely, since then. He had it painted with iodine some years ago, but without any beneficial result. The right eyeball was now very much protruded, and he saw double in consequence of the prolongation of the visual axis only on one side. The left orbit was perfectly healthy ; but there was a large exostosis over the nose, growing from the frontal sinus. Mr. Bryant first removed the growths from the orbit by turning down the eyeball and its appendages, and then chiselling and sawing them away piecemeal. Their aggregate size in the orbit was that of a small orange. He then removed the exostosis from the frontal sinus in the same way. These growths seemed to arise from pedicles, which were carefully cut through and removed as far as possible. They involved only the outer plate of the frontal bone, which had been absorbed to a mere shell to make room for the growths. The inner plate of bone was left untouched, and the brain, consequently, was not exposed. The wound made was very large, but was wholly external, so that little danger was apprehended from it, so far as the brain was concerned. Mr. Bryant was not sure that vision would remain in the right eye; but, as he had nat seen the optic nerve, nor done much damage to its appendages, he hoped that the eyeball would remain as useful as ever, or even improve. The eyeball would retract again, and become normal in course of time, and the man's appearance be vastly improved. After stitching up the wound, a pad of cotton-wool was placed over the eye and bandaged on. This operation occupied upwards of an hour.

Excision of the Hip- Foint.-Mr. Durham, who was to have had two cases of this sort, said that one of the patients had declined to undergo operation. He had been operated on twenty years ago for hipdisease at another hospital, when he was five years of age. Disease soon, however, reappeared in the same locality, and had continued. His limb was now shortened, wasted, and drawn up. There were three or four large sinuses leading to necrosed bone. The ence of the femur was diseased, as was the pelvis to some extent. He was. wasted, wan, and apparently fast sinking, and had no chance what. ever without the removal of the source of irritation and exhaustion ; but, as he had refused to undergo operation, nothing further could be done. Mr. Durham then removed the head of the femur in a similar case, a child six years of age. The child had been a year in another hospital without benefit, and was now in such a wretched state that little good was hoped for as the result of operation : but as this was the only possible chance of life, it was done. The leg was œedematous throughout, as was the scrotum, and the child was extremely emaciated.

\section{REVIEWS AND NOTICES.}

\section{MODERN SURGERY.*}

[Concluded from page 582 of number for Nou. 23rd.]

"THEY be the best chirurgeons which, being learned, incline to the traditions of experience, or, being empirics, incline to the methods of learning." If the wise words of the great Chancellor, which Mr. ERICHSEN prefixes to his treatise on the Science and Art of Surgery', and which are the key to the principles of its composition, were always as clearly present to the minds of other authors as they have been to his, there would be better reason to be content with the general tone and character of the surgical literature of the day. There are two important sections of Mr. Erichsen's treatise which will always claim attentinn and respect, as examples of a happy combination of fulness of learning with well weighed clinical experience; they are those which deal with Injuries of the Head and with Surgical Aneurisms. Accepted doctrines are stated with a perceptible reference to their mode of growth and to their historic as well as their modern and temporary relations. Mr. Erichsen is not of opinion "that the theories of one man are of no more importance than those of another". He is familiar with the work, and not merely with the names, of Anel, of Guattani, of Desault, Brasdor, and Deschamps; and nowhere can the surgeon find a clearer guide to the latest results of science and practice in this still progressive branch of surgery, than in Erichsen's excellent chapters; nor, indeed, could any better example be found of the way in which a liberal study of the labours of the great men of the past throws a more perfect light upon the results of modern labourers. Broca's doctrine of active (laminated) and passive (or merely coagulated) clots will be found lamentably misstated in Bryant's manual, adopted unwisely in Hamilton's treatise, tediously catalogued in Gross's System of Surgery, and occupying its true place in the history of our art in Erichsen. In one of those marvello'ss sentences in which he characteristically darkens wisdom, Mr. Bryant writes: "Broca has described the laminated coagulum lining the sac as 'active clot', and the soft coagulum in the centre 'passive clot', from the idea that this latter is a mere post mortem deposit, and not a vital one. This view can hardly be correct, as there can be little doubt that, in all cases of aneurism that are rapidly curesi by pressure, digital or otherwise, the consolidation of the sac must be due to the simple coagulation of the blood in the sac and its subsequent ind 1 ration and contraction; for a few hours are clearly too short a time for the laminated coagulum to form in any other way." So extraordinary a travesty of a doctrine, and so singular a correction of it, have rarel: been presented as traps for the unwary student. If any candidate for the diploma of the College of Surgeons were to depend upon this manual for his knowledge of the theory of the cure of aneurism by

* The Principles and Practice of Surgery. By Frank Hastings Hamilton. New York: William Wood. 1872

The Science and Art of Surgery. By John E. Erichsen. Sixth Edition. Lrndon: Longmans. 1872

New Edition. By Samuel A. Lane. Vol. 861 ; vol. ii, 1872 . London: Longmans.

The Practice of Surgery: a Manual. By Thomas Bryant. London: Churchills. 1872 .

A System of Surgery. By Samuel D. Gross, M.D. Fifth Edition. Philadelnhia : H. C. Lea. 1872 . 